\title{
Mapping the base of sand dunes using a new design of land-streamer for static correction applications
}

\author{
Hashim Almalki • Tariq Alkhalifah
}

Received: 16 August 2011 / Accepted: 16 April 2012/Published online: 16 May 2012

(C) The Author(s) 2012. This article is published with open access at Springerlink.com

\begin{abstract}
The complex near-surface structure is a major problem in land seismic data. This is more critical when data acquisition takes place over sand dune surfaces, where the base of the sand acts as a trap for energy and, depending on its shape, can considerably distort conventionally acquired seismic data. Estimating the base of the sand dune surface can help model the sand dune and reduce its harmful influence on conventional seismic data. Among the current methods to do so are drilling upholes and using conventional seismic data to apply static correction. Both methods have costs and limitations. For upholes, the cost factor and their inability to provide a continuous model is well realized. Meanwhile, conventional seismic data lack the resolution necessary to obtain accurate modeling of the sand basement. We developed a method to estimate the sand base from land-streamer seismic acquisition that is developed and geared to sand surfaces. Seismic data acquisition took place over a sand surface in the Al-Thumamah area, where an uphole is located, using the developed land-streamer and conventional spiked geophone systems. Land-streamer acquisition not only provides a more efficient data acquisition system than the conventional spiked geophone approach, but also in our case, the land-streamer provided better quality data with a broader frequency bandwidth. Such data enabled us to do accurate near-surface velocity estimation that resulted in velocities
\end{abstract}

H. Almalki $(\bowtie)$

Oil and Gas Research Institute, King Abdulaziz City for Science and Technology (KACST), Riyadh, Saudi Arabia

e-mail: halmalki@kacst.edu.sa

T. Alkhalifah

Physical Sciences and Engineering Department, King Abdullah University of Science and Technology (KAUST), Thuwal, Saudi Arabia that are very close to those measured using uphole methods. This fact is demonstrated on multiple lines acquired near upholes, and agreement between the seismic velocities and the upholes is high. The stacked depth seismic section shows three layers. The interface between the first and second layers is located at $7 \mathrm{~m}$ depth, while the interface between second and third layers is located at $68 \mathrm{~m}$ depth, which agrees with the uphole result.

Keywords Land-streamer - Static correction . Seismic velocity

\section{Introduction}

High-resolution seismic reflection techniques are valuable tools for nondestructive imaging of the shallow subsurface. These techniques are usually applied to estimate near-surface geotechnical parameters when information about the spatial distribution of seismic velocities in heterogeneous unconsolidated sediments is required for a wide variety of near-surface environmental and engineering applications (e.g., Knödel et al. 1997; Butler 2005; Kirsch 2006; Lehmann 2007). However, it lacks redundancy measures usually considered in conventional methods. Using highresolution land-streamer seismic acquisition for special applications over a small area can help us regain the redundancy associated with conventional acquisition. In addition, estimating the near-surface velocity using highresolution seismic techniques instead of upholes reduces cost and spares the environment from drilling hazards (Cox 1999).

A high-resolution seismic reflection survey was performed in the Al-Thumamah area, $60 \mathrm{~km}$ north of central Riyadh, as shown in Fig. 1. In this figure, a well and its 
Fig. 1 A map showing the location of the seismic line, direction of the seismic line, location of the well and coordinates of the well

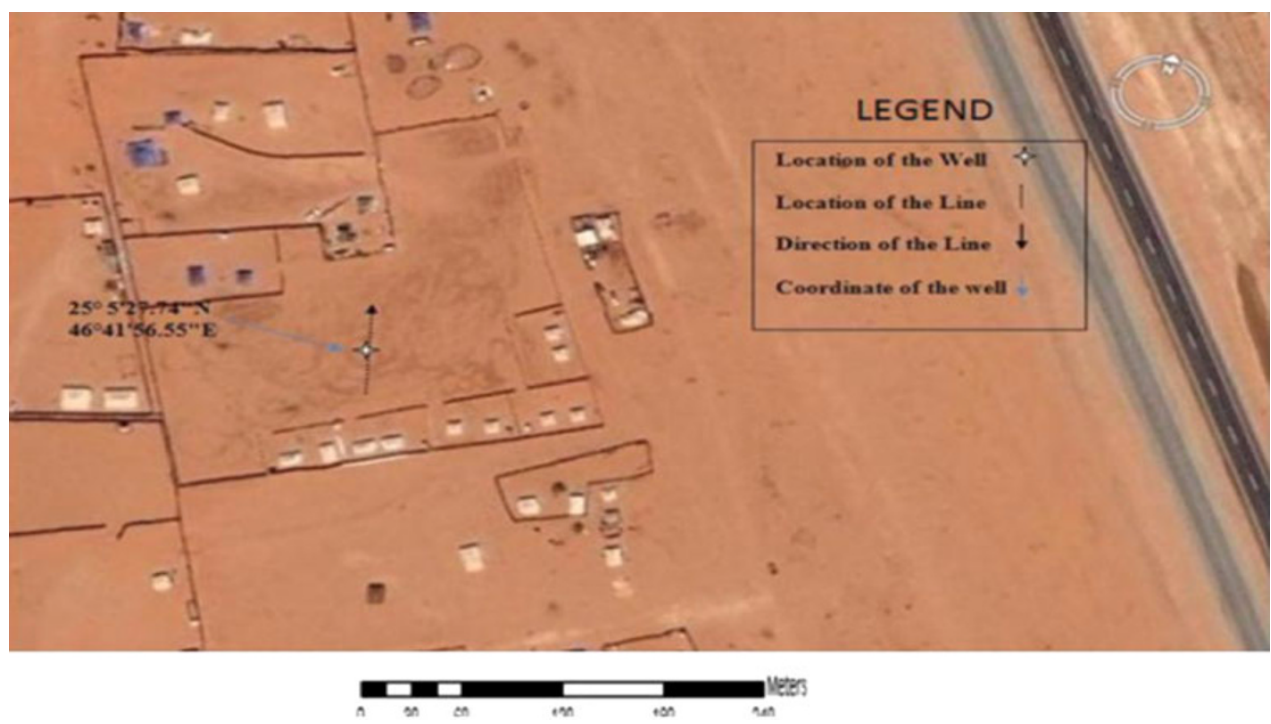

Table 1 Comparison between conventional methods for estimating the base of sand dunes

\begin{tabular}{llc}
\hline Uphole method & Conventional seismic reflection method & Seismic refraction method \\
\hline This method is costly and time consuming & This method is also costly and time consuming $\begin{array}{c}\text { This method needs a considerable depth below } \\
\text { the surface }\end{array}$ \\
$\begin{array}{l}\text { This method does not provide lateral } \\
\text { information }\end{array}$ & $\begin{array}{c}\text { This method fails to achieve necessary resolution } \\
\text { for near surface, i.e., }<50 \mathrm{ft} \text { depth }\end{array}$ & $\begin{array}{c}\text { The velocity needs a suitable factor to convert } \\
\text { to an equivalent vertical velocity }\end{array}$ \\
$\begin{array}{l}\text { This method is difficult to position uphole } \\
\text { drilling rigs near the tops of dunes }\end{array}$ & $\begin{array}{c}\text { This method produces noisy results up to } 100 \mathrm{ft} \\
\text { depth }\end{array}$ & $\begin{array}{c}\text { There are some constraints on the refraction } \\
\text { approach }\end{array}$ \\
$\begin{array}{l}\text { This method is awkward to drill in soft sand } \\
\text { Drilling could change the physical properties } \\
\text { of the subsurface }\end{array}$ & & \begin{tabular}{c} 
\\
\hline
\end{tabular}
\end{tabular}

coordinates are displayed along with a 2D seismic profile. The complex geologic structure of the near-surface is a tangible problem for collecting land seismic data when the acquisition takes place over a sand dune. The base of the sand dune acts as a mask of energy that could adversely affect the conventional acquisition of seismic data, scattering of energy from the dune faces and changing velocities within the dunes. By mapping the base of the sand dune, we can model the sand dune and also reduce its harmful influence on seismic data. Present methods used for static correction applications are drilling upholes and using the conventional spiked geophone method. Both of these methods have limitations despite their cost effectiveness. For upholes, the cost factor and the inability of upholes to provide a continuous model are well understood. Meanwhile, conventional seismic data lack the resolution necessary to obtain accurate modeling of the sand basement. A comparison of these methods is summarized in Table 1. Sand models and velocities are essential for better near-surface correction of conventional seismic data processing and are used to constrain refraction based on static solutions. The methods traditionally used to compute datum static corrections are based on a near-surface model consisting of the surface elevation, the base of weathered layer and the velocity in and below the weathered layer.

The ultimate goal of the present study is to establish the ability and cost effectiveness of the new design of a landstreamer, compared with conventional methods, to delineate an accurate sand dune model below the weathered layer as required to apply the appropriate static corrections for conventional seismic data processing.

\section{New technology}

Our objective was to build a structural and approximate velocity model of sand dunes in a reasonably cost-effective way for appropriate static correction applications. We developed a new design for the land-streamer that works in a sand dune environment. Therefore, we called it the sandstreamer. The mechanism for this technique is shown in Fig. 2. The system is made of geophones carrying metal plates that are relatively heavy and loosely connected to flexible metal sheets for stability and mobility. This 
Fig. 2 The mechanism used for the new technique

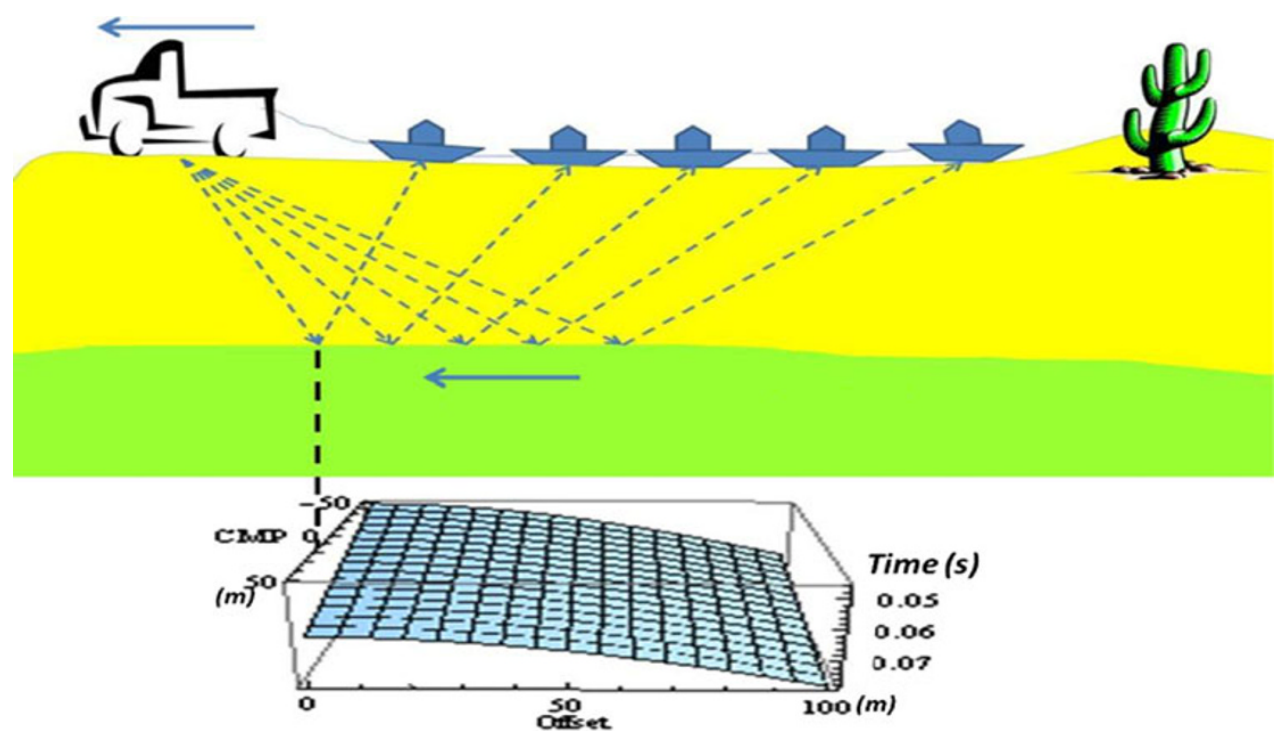

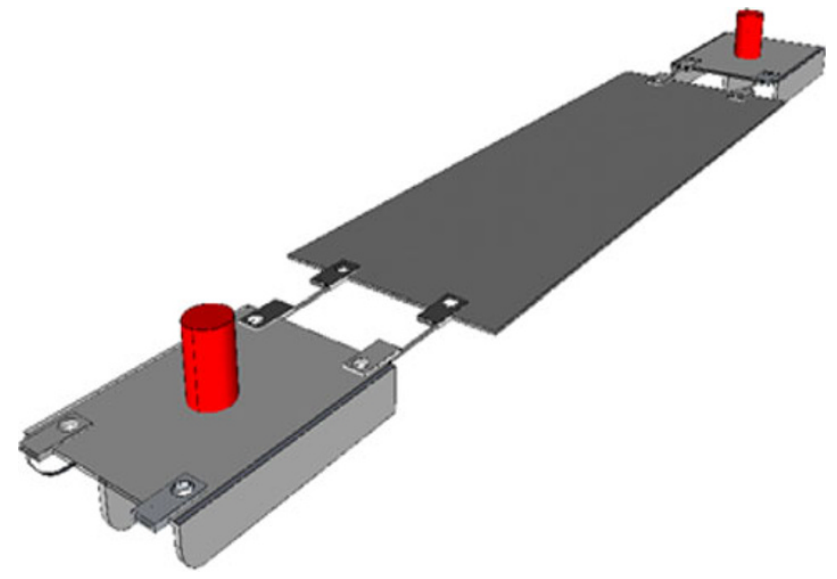

Fig. 3 A model of the sand-streamer

mechanism provides us with a high dominant frequency and a broader frequency bandwidth. Its shape and configuration are optimized to work best over sand dunes. The configuration has two special features: a smooth shape for ease in mobility and heavy metal plates for the best coupling. The model of sand-streamer is shown in Fig. 3.

Our method consists of an acquisition method and a complementary processing scheme. After identifying a desired location for investigation, we began acquiring data by placing a group of high-resolution sensors, which were placed on specially designed mobile plates (land streamer), along a line or set of lines with sensor spacing $\Delta g$ being constant or variable (increasing with offset distance from the source). Next, a wave field source was ignited in front of the line of sensors at regular spacing intervals. The source and sensors were dragged and moved with a regular source spacing of $\Delta s$. The relevant variables and parameter acquisition comparison are shown in a glossary in Table 2 .
Table 2 Relevant variables and comparison between conventional and high-resolution seismic reflection techniques

\begin{tabular}{llll}
\hline Parameter & Symbol $\begin{array}{l}\text { Conventional } \\
\text { method }\end{array}$ & $\begin{array}{l}\text { High-resolution } \\
\text { method }\end{array}$ \\
\hline Receiver interval & $\Delta g$ & $\sim 25 \mathrm{~m}$ & $\sim 1 \mathrm{~m}$ \\
Shot location & $s$ & $>10 \mathrm{~km}$ (range) & $\sim 120 \mathrm{~m}$ (range) \\
Source interval & $\Delta s$ & $\sim 25 \mathrm{~m}$ & $\sim 1 \mathrm{~m}$ \\
Receiver location & $g$ & $>10 \mathrm{~km}$ (range) & $\sim 120 \mathrm{~m}$ (range) \\
CMP interval & $m$ & $15 \mathrm{~m}$ & $0.5 \mathrm{~m}$ \\
Zero-offset time & $t_{0}$ & $6 \mathrm{~s}(\mathrm{max})$ & $0.4 \mathrm{~s}$ (max) \\
Dominant frequency & $f_{\text {peak }}$ & $25 \mathrm{~Hz}$ & $150 \mathrm{~Hz}$ \\
Time sampling & $\Delta t$ & $4 \mathrm{~ms}$ & $0.5 \mathrm{~ms}$ \\
Reflector ray & $p$ & & \\
parameter & & & $\sim 120 \mathrm{~m}$ (max) \\
Offset & $X=$ & $\sim 3,000 \mathrm{~m}(\max )$ & $\sim($ average) \\
Stacking velocity & $v$ & $3,000 \mathrm{~m} / \mathrm{s}$ & $($ average) \\
Traveltime & $t$ & &
\end{tabular}

The data acquired based on the above acquisition configuration are small in size compared with data acquired through conventional processing and can be handled easily and loaded onto a computer that can execute the following processing flow in real time:

- Gain to correct for geometrical spreading.

- Band bass filter to concentrate on high frequencies, or a variation thereof necessary to obtain good-quality, high-resolution data.

Using the classical form for the description of traveltime moveout in the presence dip given by 
$t=\sqrt{t_{0}^{2}+\frac{\cos \varphi(g-s)^{2}}{v^{2}}}$

where $\varphi$ is the reflector dip, we described a summation surface for all acquired data. To do so, we converted Eq. (1) as a function of ray parameter $p$ and used $X$ as follows:

$t=\sqrt{t_{0}^{2}+\frac{\left(1-v^{2} p^{2}\right) X^{2}}{v^{2}}}$

Noting that the intent is a summation over multiple CMPs covering a window governed by the desired resolution, the zero-offset time $t_{0}$ was replaced by a dip-dependent $t_{0}$, resulting in

$t(m, X, v, p)=\sqrt{\left(t_{0}+m p\right)^{2}+\frac{\left(1-v^{2} p^{2}\right) X^{2}}{v^{2}}}$

which describes the summation surface for the semblance search over velocities and ray parameters for a given source and receiver combination for each input trace.

For the 3-D case, $m$ and $X$ became vectors on the 2-D surface with components $\left(m_{x}, m_{y}\right)$ and $\left(X_{x}, X_{y}\right)$, respectively. In addition, we searched for both components of the ray parameter $\left(p_{x}, p_{y}\right)$ as follows:

$$
\begin{aligned}
& t\left(v, p_{x}, p_{y}\right) \\
& =\sqrt{\left(t_{0}+m_{x} p_{x}+m_{y} p_{y}\right)^{2}+\frac{\left(1-v^{2} p_{x}^{2}\right) X_{x}^{2}+\left(1-v^{2} p_{y}^{2}\right) X_{y}^{2}}{v^{2}}}
\end{aligned}
$$

which resulted in a 3-D search that may require advanced search methods such as automated ones.

The sensitivity to the velocity in these surface searches is clear, as they are equivalent to the normal stacking velocity analysis. Nevertheless, we achieved higher stability and resolution prompted by the better signal-to-noise ratio from the extra summation over CMP gathers than what is usually attainable through conventional methods.

\section{Data acquisition}

The seismic data acquisition took place over a sand surface with loose sandy sediments. The high-resolution conventional spiked geophone survey and land-streamer seismic data were acquired. The land-streamer technique is costeffective, and it is easy to perform surveying in less time (Miller et al. 2005; Van der Veen et al. 2001). The same acquisition parameters (shown in Table 3) were used for the high-resolution land-streamer and conventional spiked geophone surveys.

A total of 48 geophones were used for the high-resolution land streamer. We started acquiring data by placing a group of high-resolution sensors on specially designed mobile plates (the land streamer) along a line or set of the
Table 3 Acquisition parameters

\begin{tabular}{ll}
\hline Receiver interval & $1 \mathrm{~m}$ \\
Source interval & $1 \mathrm{~m}$ \\
CMP interval & $0.5 \mathrm{~m}$ \\
Spread & Split \\
Geophone type & $40 \mathrm{~Hz}$ \\
Sample rate & $0.25 \mathrm{~ms}$ \\
Maximum offset & $48 \mathrm{~m}$ \\
Minimum offset & $1 \mathrm{~m}$ \\
Source type & Sledgehammer
\end{tabular}

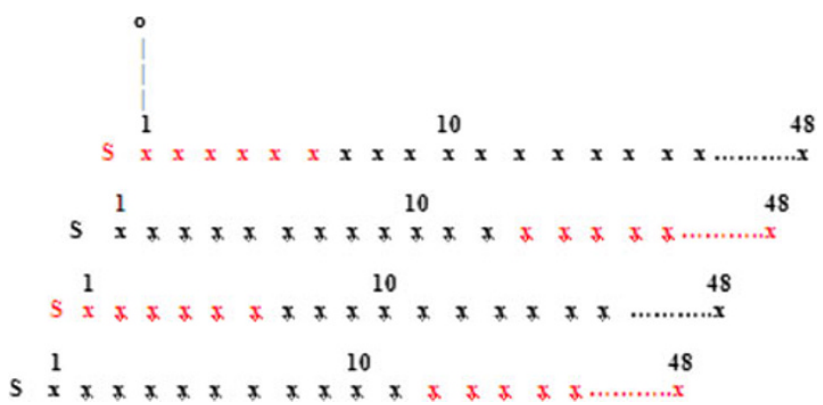

Fig. 4 The land-streamer with 48 channels. $O$ is the origin, $S$ is the source location and $x$ depicts the location of the geophone as it moves forward over time

lines with sensor spacing $\Delta g$ being constant or variable (increasing with offset distance from source). Next, a wave field source was ignited in front of the line of sensors at regular spacing. The source and sensors were dragged and moved with a regular source spacing of $\Delta s$. The spread layout was chosen to be end-on. The geometrical pattern is shown in Fig. 4. A few field snaps are shown in Fig. 5. The data were recorded in SEG-D format and later sent to a processing team. This land-streamer technique with highly mobile sensors reduces costs and also speed acquisition, which is beneficial in the seismic industry.

\section{Data processing}

Seismic data processing is important for filtering and collecting velocity information about the subsurface. Different techniques are used for processing, but the methodology is the same for getting a better signal-to-noise ratio (Yilmaz 2001; Sheriff and Geldart 1999). The software used for processing was ProMAX. Both the collected high-resolution land-streamer and conventional data were subjected to the same sequence of processing steps and parameters started by inputting SEG-D formatted data into the software. A geometry was built for this sequence and assigned to the data. The processing flow followed for these datasets is given in Fig. 6. Because energy penetrated into the 
Fig. 5 Field photographs and the layout of the streamer
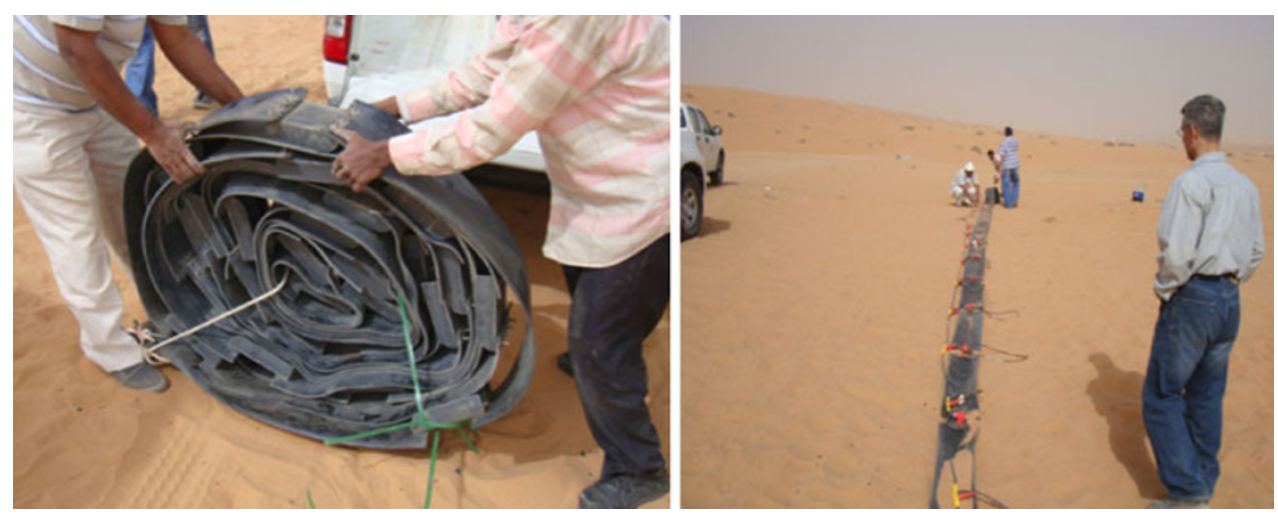

subsurface, it was attenuated, and surface wave noise was also recorded in the data. The data were filtered to acquire a better signal-to-noise ratio. The data were deconvolved to obtain the desired signal. Due to the small size of the data, processing did not take a long time. The extra summation over CMP gathers were performed to obtain more stability and a better signal-to-noise ratio. Velocity analysis was performed to obtain semblance maxima. The same velocity was used for stacking.

\section{Results and discussions}

The results can be discussed through a comparison of the high-resolution land-streamer method with other conventional methods. Examples are given below.

First breaks

A comparison of raw images of the high-resolution landstreamer and the conventional spiked geophone method shows the great amount of clarity in the land-streamer one, possibly because the geophones in the land streamer are at the surface level and higher. The geophones are well coupled due to their weight and also their shape, which is ideal for obtaining a complete image from the subsurface. Therefore, a high quality of the first breaks was achieved using this method, thus giving a true picture of the refractor. The comparison is shown in Fig. 7a-c.

Frequency spectrum

Frequency is the main difference between the conventional spiked geophone method and the land streamer one. A much broader range of frequencies was recorded by the land-streamer method, which is a result of a high-level coupling of the geophone and its shape as shown in Fig. 8a. This broader range is the reason why the conventional spiked method did not perform as well here due to poor coupling over the sand surface; it loses high-frequency

\section{Disk Data Input}

True Amplitude Recovery

Surface Wave Noise Attenuation

Filtering

Deconvolution

Elevation Statics

Velocity Analysis

Stack

Fig. 6 The processing flow that was followed to process landstreamer data

data. The peak frequency recorded by the conventional spiked geophone method was approximately $60 \mathrm{~Hz}$, and the peak frequency recorded by the land-streamer method was $90 \mathrm{~Hz}$ as shown in Fig. 8b and c, respectively. The bandwidth frequency of land-streamer data was broader than the bandwidth frequency of the conventional spiked geophone method.

\section{Velocity spectrum}

One of our main objectives was to build a velocity model because the near-surface, especially in the case of a sand dune environment, is heterogeneous. Velocity invariably varies both laterally and vertically. The sensitivity to velocity in these surfaces is clear, as the sensitivity is equivalent to the normal stacking velocity analysis. An approximate velocity model is needed to map the sand dune base. For this, data were conducted the velocity analysis to select the best approximate velocity. The 
Fig. 7 a-c Raw data gathered displays of a few shots are shown from the conventional spiked geophone (left) and land streamer (right). Clearly, the first breaks are clear and easy to identify

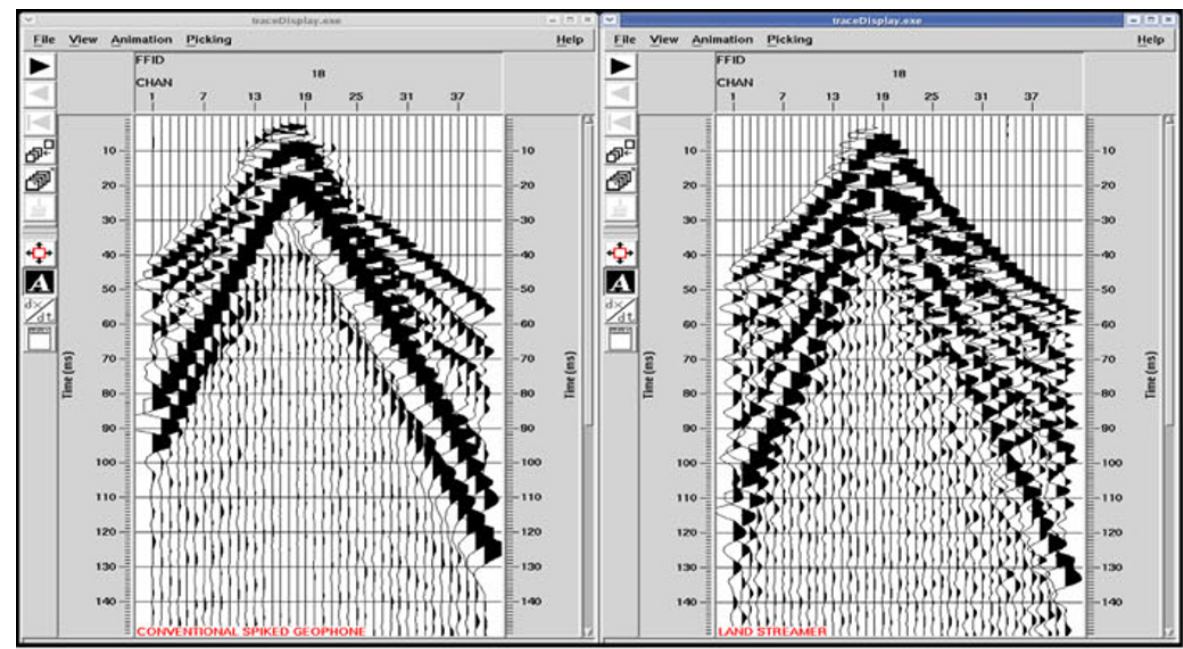

(a)

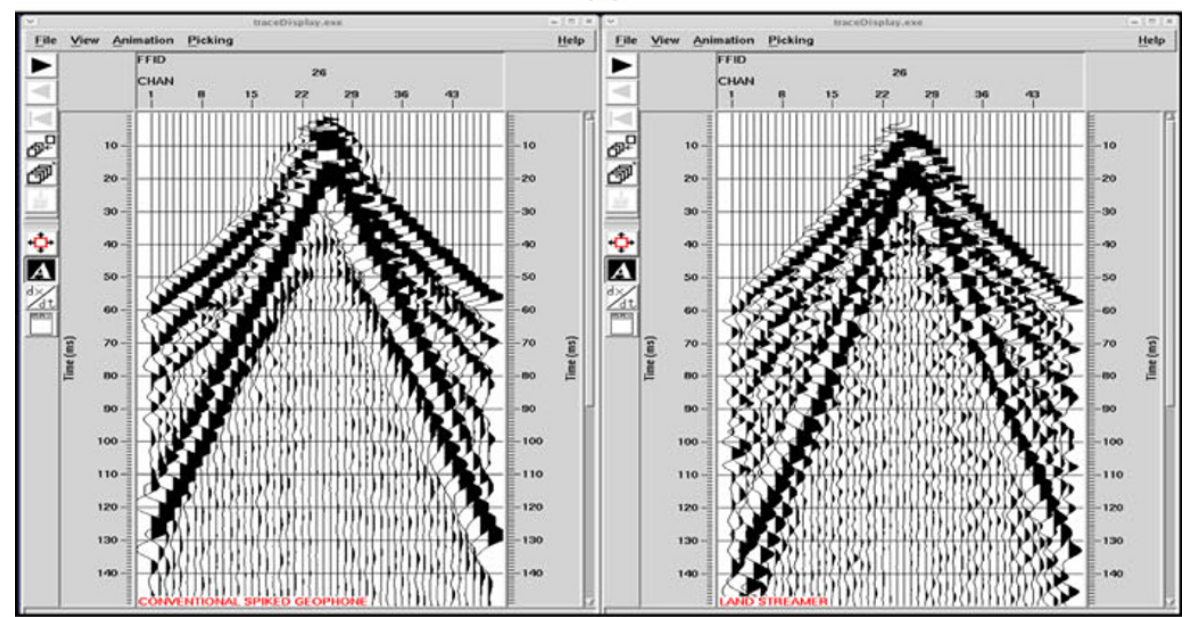

(b)

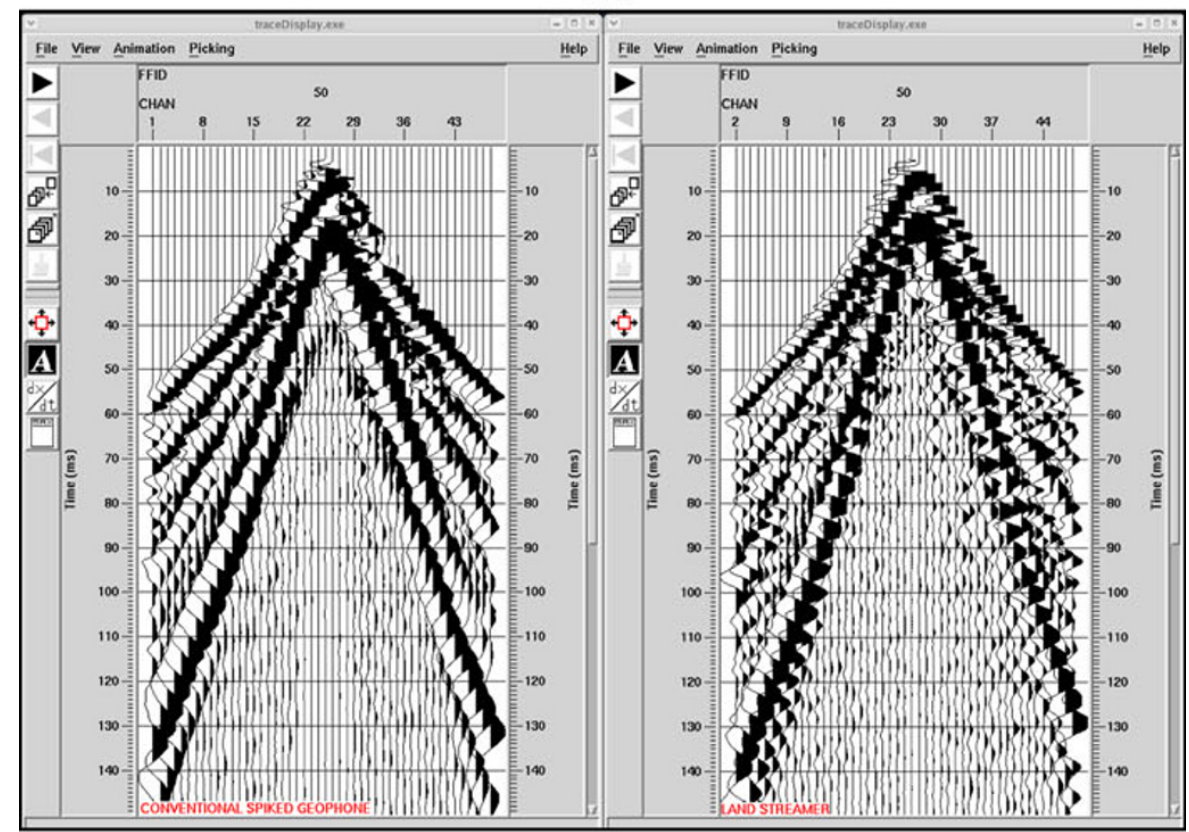

(c) 


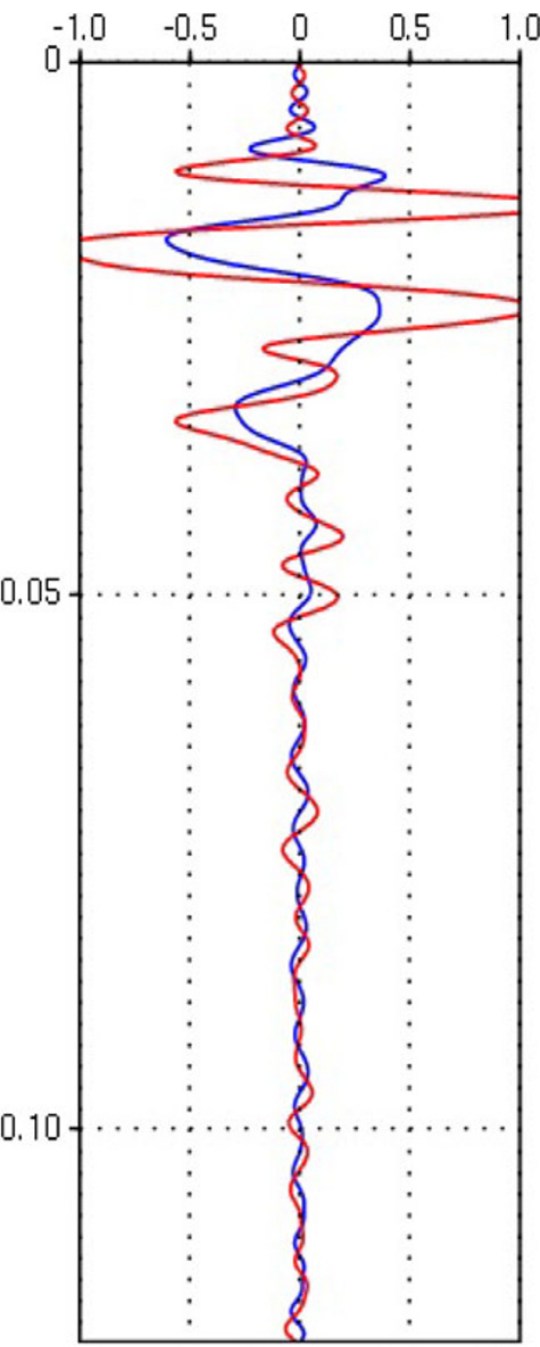

(a)

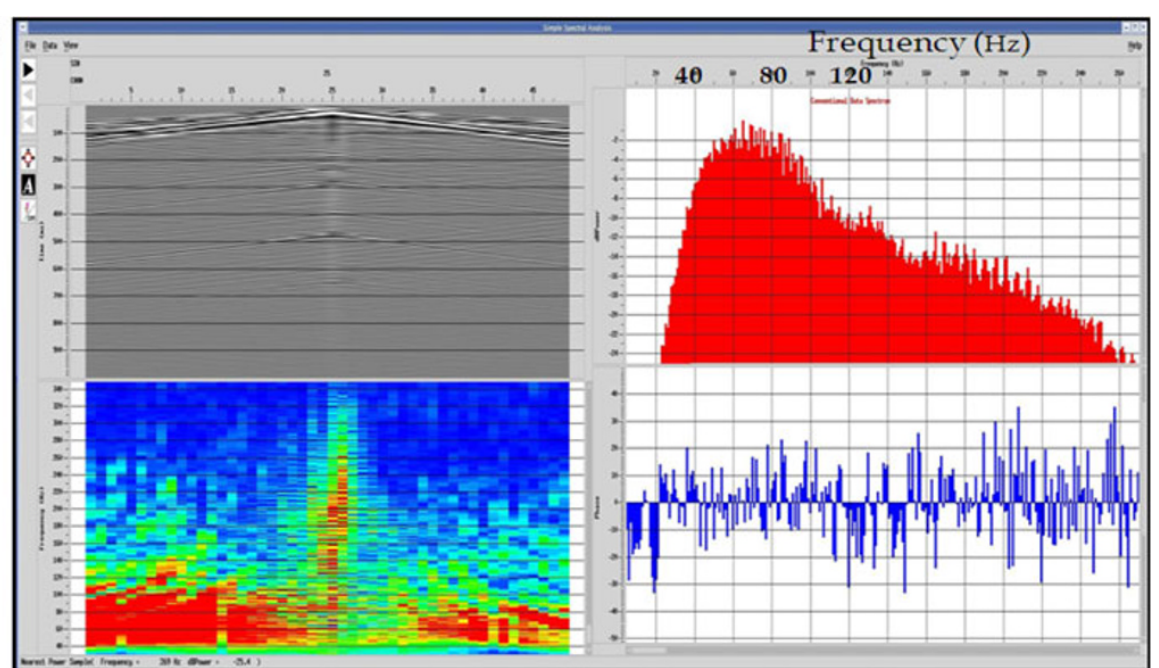

(b)

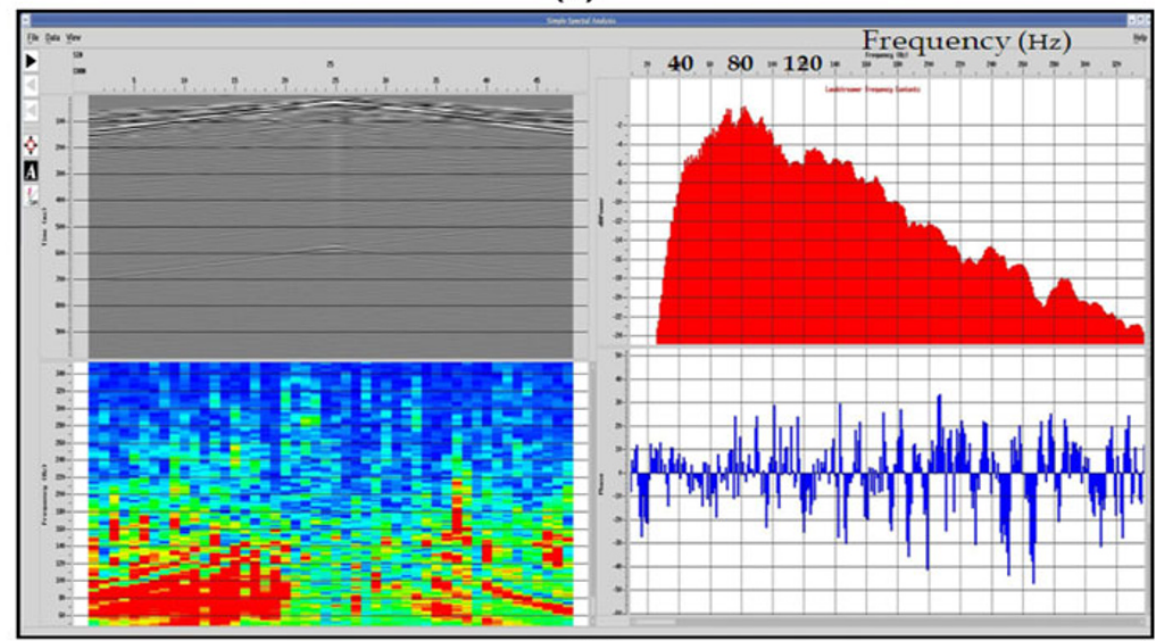

(c)
Fig. 8 a A single trace of land-streamer seismic data (red) overlain with a single trace of conventional spiked geophone data (blue). Clearly, the land-streamer seismic data is of higher frequency. b Spectral analysis of the conventional spiked geophone method,

semblance analysis resulting from the land-streamer highresolution data was used to obtain the interval velocity. Examples of semblance maxima, with the bottom of the sand corresponding to the first pick, are shown in Fig. 9. The velocity analysis was performed with high-resolution data, and appropriate velocities were picked. These velocities were also corrected for the normal moveout correction.

\section{Stack comparison}

After the velocity, the land-streamer data were stacked with it. The semblance maxima at two locations were picked and also confirmed in the stack. The extra summation over CMP gathers were performed to obtain better stability and a better signal-to-noise ratio. Clearly, the clearly showing a peak frequency of approximately $60 \mathrm{~Hz}$. c Spectral analysis of the land-streamer method, clearly showing a peak frequency of approximately $90 \mathrm{~Hz}$

stack with high-resolution land-streamer method produced a better picture than the conventional spiked geophone method as shown in Fig. 10. The streamer provided better continuity in the deeper part. A more accurate picture was chosen, which showed the shape of the base of the sand.

Time-to-depth conversion

The time section is converted into a depth section using the picked velocities. This depth section is then compared with the uphole. Exact depths of refractors are mapped as confirmed by the uphole as shown in Fig. 11. These exact depths are achievable only if the picked velocity is appropriate. The sand base and other limestone are confirmed at 7 and $68 \mathrm{~m}$, respectively. 
Fig. 9 The velocity spectrum of acquired sand streamer seismic data (left), the moveout resulting after NMO with picked velocity (middle) and stacking velocity scans (right). The interval velocity shown in black is a blocked curve.

Clearly we can see a couple of semblance maxima with the bottom of the sand corresponding to the first pick

Fig. 10 Stacked seismic sections for the sand streamer (left) and for the spiked geophone (right). Clearly, the streamer provided better continuity in the deeper part
Fig. 11 A stacked section from the sand streamer compared with an uphole check shot velocity plot, focusing on the depths of interest. Exact depths of refractors are mapped as confirmed by the uphole

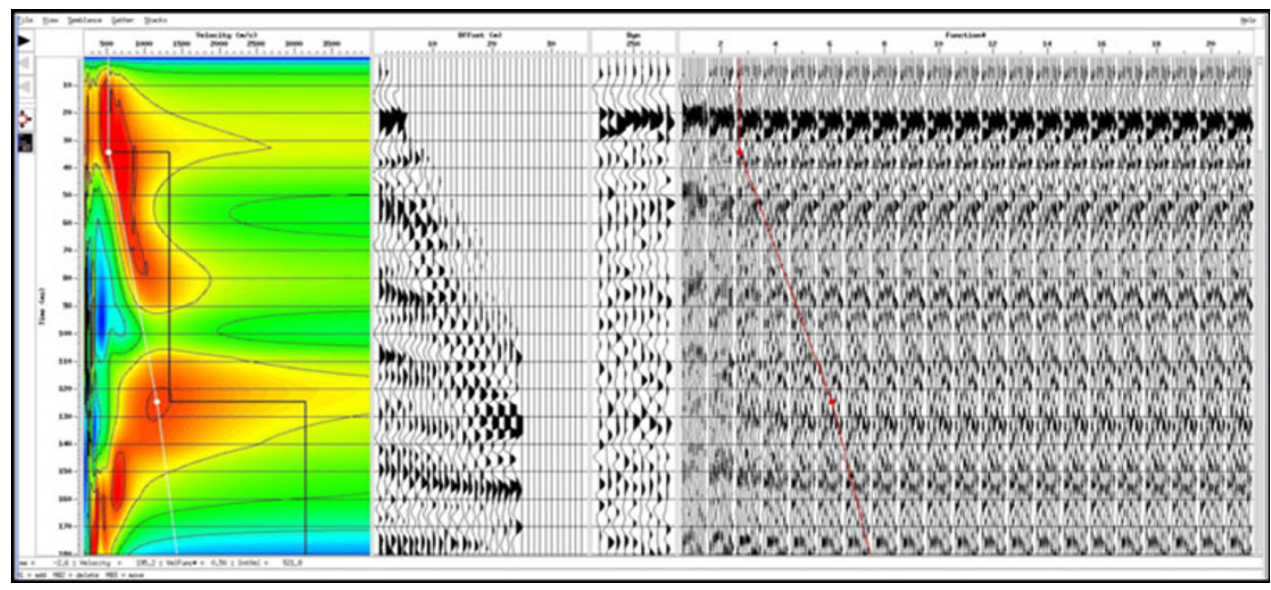

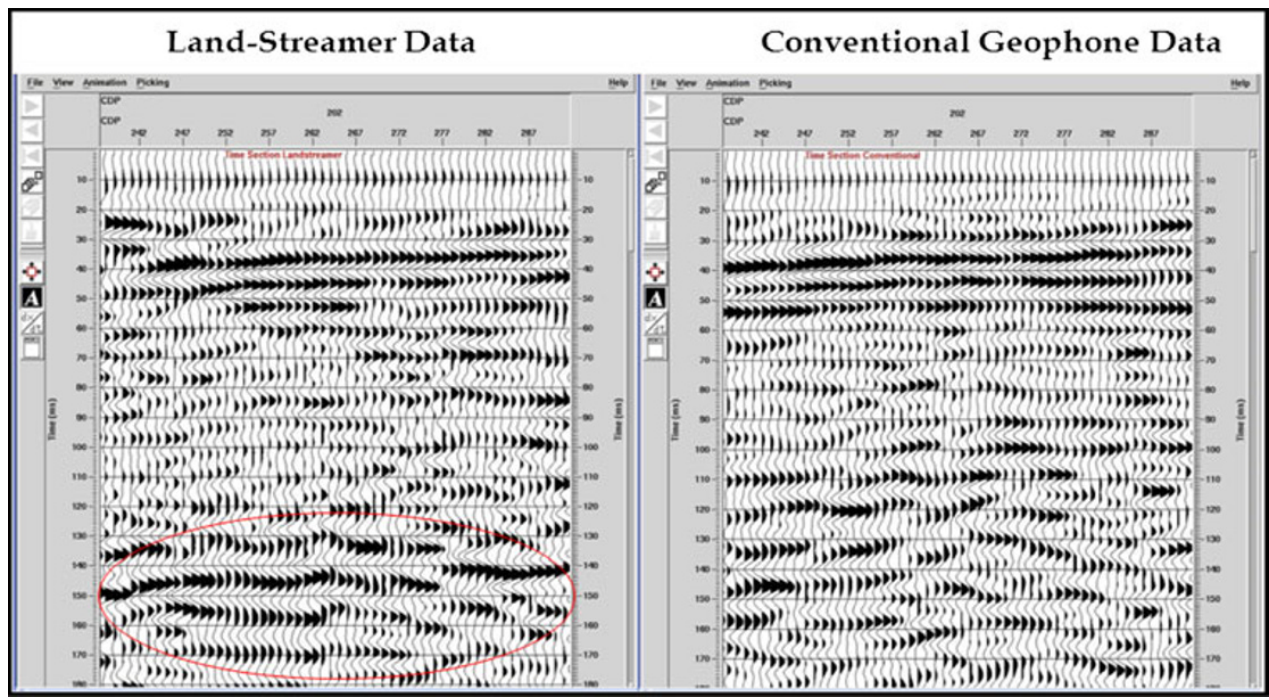




\section{Conclusions}

The results discussed above indicate that an acquisition method using a new design of land-streamer (sand-streamer) produces better results than the conventional spiked geophone method. The sand-streamer technique is reasonably cost-effective compared with other conventional techniques. Its small dataset is easy to process by computer. A broader frequency bandwidth is achievable using this sand-streamer technique. This method speeds up the acquisition system over sand dune surfaces instead of drilling upholes or planting geophones.

Therefore, this technique can replace the conventional spiked geophone method and upholes. This technique can also reduce the harmful influence of variation in spiked geophone coupling over sand surfaces. There is a need for an accurate technique to characterize the near-surface, and this high-resolution reflection technique proved to be promising.

Acknowledgments We wish to thank Saudi Aramco for providing us with the uphole data. We would like to thank King Abdulaziz City for Science and Technology (KACST), Riyadh, for support and Ibrahim Hafiz, Mohammed Almalki and Ishtiaq Hussain for their contributions.
Open Access This article is distributed under the terms of the Creative Commons Attribution License which permits any use, distribution, and reproduction in any medium, provided the original author(s) and the source are credited.

\section{References}

Butler DK (ed) (2005) Near-surface geophysics. SEG, Tulsa

Cox M (1999) Static corrections for seismic reflection surveys. SEG, Tulsa

Kirsch R (2006) Groundwater geophysics: a tool for hydrogeology. Springer, New York

Knödel H, Krummel H, Lange G (1997) Handbuch zur Erkundung des Untergrundes via Deponien und Altlasten-Band 3: Geophysik. Springer, Berlin

Lehmann B (2007) Seismic traveltime tomography for engineering and exploration applications. EAGE Publications, Houten

Miller CR, Allen AL, Speece MA, El-Werr AK, Link CA (2005) Land streamer aided geophysical studies at Saqqara, Egypt. J Environ Geophys 10:371-380

Sheriff RE, Geldart LP (1999) Exploration seismology. Cambridge University Press, pp 275-322

Van der Veen M, Spitzer R, Green AG, Wild P (2001) Design and application of a towed land streamer system for cost effective 2-D and pseudo 3-D shallow seismic data acquisition. Geophysics 66(2):482-500

Yilmaz Ö (2001) Seismic data analysis. SEG, Tulsa 